\title{
Removal of Phenolic Compounds from Olive Mill Wastewater by Microalgae Grown Under Dark and Light Conditions
}

\author{
Astrid Victoria Lindner ${ }^{1} \cdot$ Daniel Pleissner ${ }^{1}$ (i)
}

Received: 7 January 2021 / Accepted: 31 July 2021 / Published online: 9 August 2021

(c) The Author(s) 2021

\begin{abstract}
Phenolic compounds in olive mill wastewater (OMW) are considered an environmental threat due to their antimicrobial properties. Because of the metabolic versatility of microalgae, a biotic removal of these compounds seems a suitable approach. To investigate the biotic removal of phenolic compounds, the three microalgae species Chlorella vulgaris, Acutodesmus obliquus and Monoraphidium braunii were cultivated in flasks under constant light $\left(50 \mu \mathrm{mol} / \mathrm{m}^{2} \mathrm{~s}\right)$ and dark ( $1 \mathrm{~g} / \mathrm{L}$ glucose $)$ conditions in presence of different concentrations of OMW. Addition of $1 \%(\mathrm{v} / \mathrm{v})$ OMW to the culture medium was shown to be non-inhibitory or even growth enhancing, and phenolic compounds were removed by $7-21 \%$ by all tested species. Cultivations with 6\% (v/v) OMW resulted in a few exceptional experiments in fast growth $(C$. vulgaris under light, M. braunii under dark conditions) and removal of phenolic compounds (M. braunii, dark). Higher percentages (12 and 25\%, v/v) of OMW were inhibitory. Under dark conditions microalgae first consumed glucose and removed phenolic compounds in a diauxic process. Removal of phenolic compounds was favoured under light conditions. Results of this study reveal the opportunities and the challenges of a microalgae-based removal of phenolic compounds and valorization of toxic OMW.
\end{abstract}

\section{Graphic abstract}
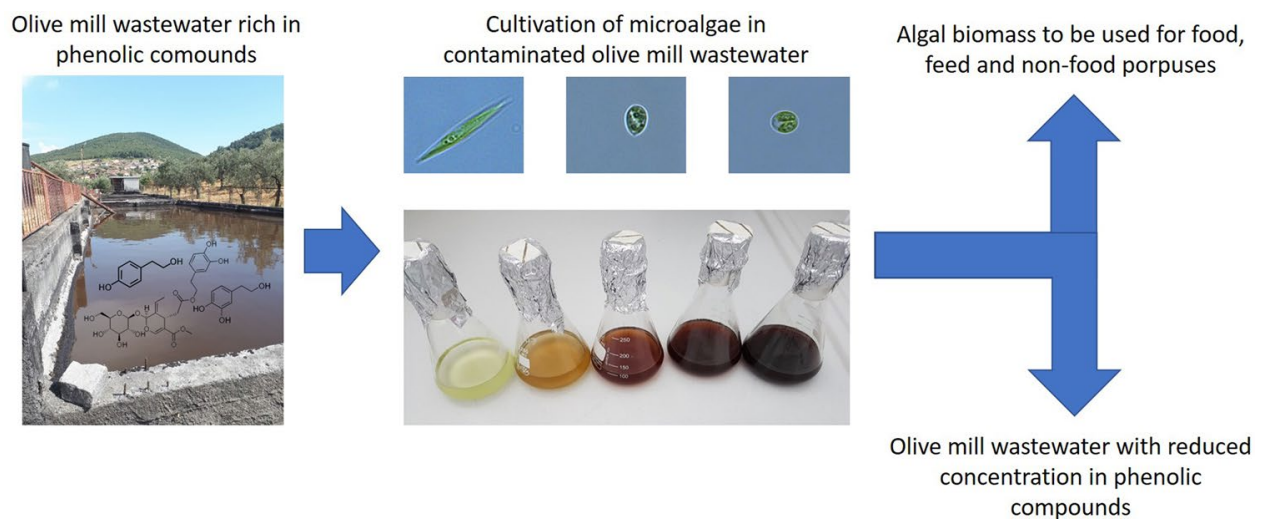

Keywords Microalgae $\cdot$ Removal $\cdot$ Olive mill wastewater $\cdot$ Phenolic compounds

\section{Statement of Novelty}

Daniel Pleissner

daniel.pleissner@leuphana.de

1 Sustainable Chemistry (Resource Efficiency), Institute of Sustainable Chemistry, Leuphana University of Lüneburg, Universitätsallee 1, C13.203, 21335 Lüneburg, Germany
Olive mill wastewater is often inappropriately managed and released uncontrolled into the environment. Particularly the high concentration of phenolic compounds causes serious environmental issues. This study considers the valorization of olive mill wastewater as a source of nutrients to be used in microalgae cultivation combined with a biotic removal 
of phenolic compounds under light and dark conditions and aims at the development of novel olive mill wastewater valorization strategies in areas with water scarcity.

\section{Introduction}

The production of olive oil generates worldwide around 30 billion $\mathrm{L}$ of wastewater originating from washing of fruits and equipment. Olive mill wastewater (OMW) possesses high biological oxygen demand $\left(\mathrm{BOD}_{5}\right)$ and chemical oxygen demand (COD) values between $35-132 \mathrm{~g} / \mathrm{L}$ and $30-320 \mathrm{~g} / \mathrm{L}$, respectively [1-3], as well as increased values of phosphorous $(0.63 \%, \mathrm{w} / \mathrm{w})$, nitrogen $(0.88 \%, \mathrm{w} / \mathrm{w})[4]$ and phenolic compounds $[5,6]$. The latter originate from olive oil, as they are formed by olive trees and enriched in the fruits. Phenolic compounds can be beneficial for human health due to their antimicrobial and antioxidant characteristics [7-9]. The increased demand in olive oil as a daily cooking ingredient shows the awareness of people regarding these positive aspects, which resulted in higher productions worldwide (2825 mio $t$ in season 2009/2010 vs 2665 mio t in season 2008/2009). However, the increased production of olive oil results in increased formation of phenol-containing OMW [10], which is mostly released into the environment [11].

Already in 1986, Paredes et al. saw the problems associated with OMW release into the environment and the possible disturbance of the microbial equilibrium in nature [12]. Phenolic compounds in OMW (found at concentrations up to $24 \mathrm{~g} / \mathrm{L}$ [6] and mostly between 1 and $10 \mathrm{~g} / \mathrm{L}$ [13]) with the most prominent representatives tyrosol, hydroxytyrosol and oleuropein [14], showed toxic effects against gram positive as well as gram negative bacteria [7,15-18]. Management of OMW so far consists, for example, of either using it as fertilizer [19-21], by evaporation in ponds or physicochemical and biological treatments [6]. However, there is no effective and feasible treatment so far [12], which considers a detoxification or takes the potential of phenolic compounds as carbon sources for microbes into account.

For the reduction of $\mathrm{BOD}_{5}$ and $\mathrm{COD}$ as well as nitrogen and phosphorous concentrations in OMW, a few approaches exist, such as the fermentation with the yeast Rhodotorula glutinis (removal of N, P, COD and BOD: 96.6\%, 80\%, $77.6 \%$, and $74.5 \%$, respectively; personal communication). This approach can potentially utilize OMW, but it is still necessary to treat the effluent further, as the phytotoxic phenolic compounds are still present. Therefore, it is important to search for a strategy to decrease the environmental disturbance by OMW and if possible, path a way to the utilization of phenolic compounds, rather than a simple remediation approach.
Microalgae might be suitable candidates for a biological OMW utilization approach. These microorganisms, predominantly Scenedesmus and Chlorella, already showed capabilities to reduce $\mathrm{COD}, \mathrm{BOD}_{5}$, phosphorus, nitrogen and ammonia in wastewater treatment [22-24]. Due to highly adaptive pathways [25-27], they may even be considered for the removal and utilization of phenolic compounds. First studies on this specific topic were already published 40 years ago by Cerniglia et al. [28]. Since then there has been an increasing amount of research around the world. However, no satisfactory solution was presented so far. As most researchers focus on the cultivation with defined, synthetic mixtures of phenolic compounds (one substance or more; [29-31]) and seldom with natural, untreated OMW, there is a lack of information about the ability of resisting inhibitory effects of the complex mixture of OMW $[13,32,33]$. Furthermore, the mechanism behind a claimed removal is often not clearly identified [34].

As microalgae are commonly known for their ability to perform photosynthesis, most studies use phototrophic cultivation approaches. As OMW already possesses a brackish structure, dark color and consequently a light reducing effect, a heterotrophic approach could be advantageous. This, however, is still to be proven. Therefore, this study will compare the cultivation of the microalgae species Chlorella vulgaris, Acutodesmus obliquus and Monoraphidium braunii in regards of growth in OMW as well as the removal of phenolic compounds in the supernatant under light and dark conditions. These species were chosen after a literature search of studies in which they were the most prominent and most promising ones in use for the removal of phenolic compounds. Furthermore, these species grow under light and dark conditions and exhibit industrial relevance as they provide high growth rates and profitable biomass constituents, such as lipids, proteins and pigments [35-40].

This work combines the application of relevant cultivation parameters, which was not conducted in this form before. As there are only a few studies, which are dealing with fresh, untreated OMW as well as the direct comparison of cultivations under light and dark conditions, this work contributes to the lack of information in this field. The additional comparison of three algal strains and their potential to remove phenolic compounds under equal culture conditions comprises important results. This may result in novel strategies to remove phenolic compounds and valorize toxic OMW in microalgae cultivation.

\section{Materials and Methods}

\section{Cultivation of Microalgae}

The microalgal species Chlorella vulgaris (SAG 211-19), A. obliquus (SAG-276-1) and M. braunii (SAG-202-7b) 
were obtained from the Culture Collection of Algae Göttingen, Germany. Strain preservation and pre-cultivation occurred in flasks on an orbital shaker (IKA KS 501 digital; 100-110 rpm), illuminated continuously by a fluorescent lamp with $50 \pm 10 \mu \mathrm{mol} / \mathrm{m}^{2} \times \mathrm{s}$ (Osram Lumilux, cool white, $18 \mathrm{~W}$ ), resulting in a temperature of $25 \pm 1{ }^{\circ} \mathrm{C}$ in 50 or $100 \mathrm{~mL}$ flasks containing sterilized AF6-medium [41]. Prior to experiments with OMW, pre-cultures for preparation of inoculum biomass were grown in $250 \mathrm{~mL}$ flasks containing $100 \mathrm{~mL}$ medium under the same conditions.

Experiments under light conditions were conducted in an incubator at $30{ }^{\circ} \mathrm{C}$ (Aqualytic TC $135 \mathrm{~S}$ incubator, Phoenix RS-OS 20 shaker, two Voltolux LED lamps, $5 \mathrm{~W}$ ) with the same photon flux density and medium as described above. For the cultivations under dark conditions another incubator was used (Biosan orbital shaker incubator ES-20/60), $1 \mathrm{~g} / \mathrm{L}$ glucose was added to promote initial growing of algae with an easily metabolizable carbon source. The concentration of $1 \mathrm{~g} / \mathrm{L}$ was chosen as a compromise between fast growth of algae and fast depletion, so that algae may than aim for phenolic compounds as other potential carbon source. Each flask was wrapped in aluminum foil.

OMW was obtained from an olive oil production site in Burhaniye, Turkey (Duzen Biological Sciences Research, Development and Production Co.). In this study, fresh OMW was used with a total phenolic compound concentration of 6.5-8 g/L (due to different batches of delivered OMW), a COD of $99.8 \mathrm{gO}_{2} / \mathrm{L}$, a $\mathrm{BOD}_{5}$ of $32.5 \mathrm{~g} / \mathrm{L}$, a phosphorus concentration of around $0.1 \mathrm{~g} / \mathrm{L}$ and a nitrogen concentration of around $0.9 \mathrm{~g} / \mathrm{L}$.

Pre-tests in 12-well plates with up to $100 \%$ OMW (v/v, $20 \%$ steps, dilution with AF6-medium) showed strong inhibitory effects on microalgal growth with $40 \%$ OMW and higher. Therefore, the following different percentages of OMW were used for the cultivation: $1 \%, 6 \%, 12 \%$ and $25 \%$ (obtained by diluting fresh OMW) resulting in total phenolic compound concentrations of $0.05-0.1 \mathrm{~g} / \mathrm{L}$, $0.35-0.6 \mathrm{~g} / \mathrm{L}, 0.6-1.1$ and $1.1-1.8 \mathrm{~g} / \mathrm{L}$, respectively (measured after inoculation). One approach with AF6-medium (without OMW) and microalgae, and one approach containing 25\% (v/v) OMW in AF6-medium without microalgae were used as controls. The OMW was pre-treated by centrifugation for $10 \mathrm{~min}$ at $4445 \times g$ and filtration prior to sterilization and usage in the cultivations. All experiments were performed in $250 \mathrm{~mL}$ flasks with a total volume of $100 \mathrm{~mL}$, a starting optical density (OD) of 0.1 and shaken at $130 \mathrm{rpm}$. The $\mathrm{pH}$ of the medium was set to $6.8-6.9$ prior cultivation, however, by adding the OMW the $\mathrm{pH}$ was reduced to $6.05-6.93$ with $1 \%(\mathrm{v} / \mathrm{v})$ OMW and down to 4.71-4.79 with $25 \%$ (v/v) OMW (manual $\mathrm{pH}$ measurement of samples after inoculation). The duration of the experiment was set to 10 days to achieve growth curves ending before death phase, avoiding inefficient slower growth after exponential phase, but cultivations long enough to make out the effect of removal of the phenolic compounds after glucose depletion. Daily samples were taken under sterile conditions and stored in a refrigerator at $-20{ }^{\circ} \mathrm{C}$ until analysis.

All cultivations were carried out in triplicate and mean values of all parameters measured as well as standard deviations are shown in the "Results and Discussion" section.

\section{Determination of Growth}

Microalgal growth was monitored daily by measuring the optical density (OD) at $750 \mathrm{~nm}$ using a spectrophotometer (Pharmacia LKB, Ultrospec III and Macherey-Nagel, Nanocolor UV/Vis II). Distilled water was used as blank, as corresponding dilutions of OMW resulted in less reliable results (different batches, changes during cultivations). The OD was not strictly following the correlation to biomass dry weight, it was, however, sufficient enough to visualize growth.

\section{Analytics}

For the determination of the concentration of phenolic compounds in the supernatant, the Folin-Ciocalteu (FC) assay was applied. For this purpose, the samples were centrifuged for $5 \mathrm{~min}$ at $6720-8064 \times g$. The FC assay was conducted according to Atanassova [42], however, downsized to a total volume of $5 \mathrm{~mL}$ : To $1.8 \mathrm{~mL}$ demineralized $\mathrm{H}_{2} \mathrm{O}$ in a $10 \mathrm{~mL}$ glass tube, $0.2 \mathrm{~mL}$ supernatant and $0.2 \mathrm{~mL} \mathrm{FC}$ reagent were added. After stirring on a vortex mixer, the mixture was placed in the dark at room temperature $\left(20 \pm 1^{\circ} \mathrm{C}\right)$ for $5 \mathrm{~min}$. Hereafter, $2 \mathrm{~mL}$ of a $7 \%(\mathrm{w} / \mathrm{v})$ aqueous $\mathrm{Na}_{2} \mathrm{CO}_{3}$ solution was added for neutralization and development of the typical blue color, as well as $0.8 \mathrm{~mL}$ demineralized $\mathrm{H}_{2} \mathrm{O}$ to reach $5 \mathrm{~mL}$ total volume. The mixture was vortexed again and kept for an incubation time of $90 \mathrm{~min}$ in the dark. Subsequently the mixture was measured spectrophotometrically at $750 \mathrm{~nm}$. The concentration of phenolic compounds was determined by using a calibration curve prepared with tyrosol solution of known concentration.

Glucose was determined using HPLC (Shimadzu: LC10AD pump, SIL-10AD auto-sampler, CTO- 10AD oven, refractive index detector RID-20A, CBM-20A communication module): $10 \mu \mathrm{L}$ of sample was injected in an Aminex HPX-87H column $(300 \mathrm{~mm} \times 7.8 \mathrm{~mm})$ and eluted isocratically with $0.4 \mathrm{~mL} / \mathrm{min} 5 \mathrm{mM} \mathrm{H}_{2} \mathrm{SO}_{4}$ at $27{ }^{\circ} \mathrm{C}$. Calibration curve was generated with pure glucose solution of known concentration.

All measurements were carried out in triplicate and mean values of all parameters measured as well as standard deviations are shown in the "Results and Discussion" section. 


\section{Statistics}

Statistical investigation of growth of algae among replicates was carried out using One-Way-ANOVA and the software SigmaPlot vs 12 . For One-Way-ANOVA, OD values from three repeated cultivations were averaged and compared pairwise. p-values are shown in section "Results and Discussion". Statistical investigation of removal of phenolic compounds among replicates was carried out using a linear regression and the software Excel. For linear regression, concentrations of phenolic compounds from three repeated cultivations were averaged and plotted against time (not shown). Correlation coefficients are shown in section "Results and discussion".

\section{Results and Discussion}

In the following the growth of the microalgae $C$. vulgaris, A. obliquus and M. braunii in OMW as well as their ability to remove phenolic compounds from the supernatant under light and dark conditions will be discussed. Removal percentages $<5 \%$ are neglected and marked as "no removal (n.r.)", as these values were in the divergence of measurements. Furthermore, the glucose consumption during the cultivations under dark conditions is shown to state if mixotrophic growth occurs (co-consumption of glucose and phenolic compounds) or if two consecutive heterotrophic steps happen (diauxie), and whether the presence of glucose, as an easily consumable carbon source, can have a positive impact on the removal of phenolic compounds and valorization of OMW. It is to be noted, that the cultivations with $25 \%(\mathrm{v} / \mathrm{v})$ OMW and higher concentrations did not show any development in growth and removal, and thus are not shown. Microalgal growth, removal of phenolic compounds and glucose consumption for the three strains are displayed in Fig. 1 for the cultivation under dark and Fig. 2 for the cultivation under light conditions. Growth rates and percentages of phenolic compounds removal are summarized in Table 1.

\section{Growth in OMW}

\section{Cultivation Under Dark Conditions}

The addition of $1 \%(\mathrm{v} / \mathrm{v})$ OMW (equivalent to $0.05 \mathrm{~g} / \mathrm{L}-0.1 \mathrm{~g} / \mathrm{L}$ phenolic compounds) has no negative effect on the growth of either microalga (Fig. 1 A, D and G), which corresponds to the earlier findings of Di Caprio et al. in 2018 [43]. In their study the cultivation of Scenedesmus sp. under dark conditions with $0.1 \mathrm{~g} / \mathrm{L}$ phenolic compounds derived from OMW showed similar growth to the control. In our study, all algae showed similar growth rates in control medium and 1\% (v/v) OMW (Table 1). A further increase in OMW concentration had a disadvantageous impact on the growth of all microalgae species under dark conditions, which also corresponds with Di Caprio et al. results from 2018. Here, $0.5 \mathrm{~g} / \mathrm{L}$ of extracted OMW phenolic compounds led to complete growth inhibition [13]. In our study, only $M$. braunii was found to grow in $6 \%(\mathrm{v} / \mathrm{v})$ OMW at an average rate of $0.231 / \mathrm{d}$. However, it should be admitted that in one experiment $M$. braunii did grow at a rate of $0.641 / \mathrm{d}$, which is comparable with the cultivations in $1 \%(\mathrm{v} / \mathrm{v}, 0.691 / \mathrm{d})$ OMW and control $(0.711 / \mathrm{d}$, Table 1$)$. Contrarily, dark cultivations of all algae in $12 \%(\mathrm{v} / \mathrm{v})$ OMW did not show any growth.

Studies by Kessler $[44,45]$ revealed that no growth inhibition of selected algae occurs down to a $\mathrm{pH}$ of 4 , while studies from Hodaifa et al. showed that maximal growth rate decreased by $39 \%$ for the microalga Scenedesmus obliquus cultivated in $5 \%(\mathrm{v} / \mathrm{v}) \mathrm{OMW}$, if the $\mathrm{pH}$ is lowered to 5 or increased to 9 [46]. It seems therefore reasonable, that the higher concentration of phenolic compounds represent a higher toxicity, which is in accordance to Di Caprio et al. (2018) [43] also the responsible parameter for inhibited growth. The composition of phenolic compounds in the OMW also has a great significance regarding the toxicity. DellaGreca et al. tested different ultrafiltration and reverse osmosis fractions (diluted), as well as single compounds on Ankistrodesmus braunii and showed that compounds like catechol or ferulic acid have a significant inhibition effect on microalgal growth. Contrarily, other compounds like tyrosol and hydroxytyrosol showed no inhibition [47].

\section{Cultivation Under Light Conditions}

Investigating the growth of $C$. vulgaris, A. obliquus and $M$. braunii during cultivations under light condition reveals, that the addition of $1 \%(\mathrm{v} / \mathrm{v})$ OMW seems to be non-inhibitory (Table 1 and Fig. 2). With 1\% (v/v) OMW in the medium, the growth rate of $M$. braunii increased from $0.291 / \mathrm{d}$ (control) to $0.381 / \mathrm{d}$. A. obliquus' ' growth rate stayed the same with around $0.41 / \mathrm{d}$. C. vulgaris did grow at a rate of 0.35 $1 / \mathrm{d}$ with $1 \%(\mathrm{v} / \mathrm{v})$ OMW and at a rate of $0.431 / \mathrm{d}$ in control medium. At an OMW concentration of $6 \%(\mathrm{v} / \mathrm{v})$ C. vulgaris did even show a higher growth rate $(0.581 / \mathrm{d})$ than found in control medium and 1\% (v/v) OMW. M. braunii showed in presence of $6 \%(\mathrm{v} / \mathrm{v})$ OMW a rate of $0.31 / \mathrm{d}$, which is comparable to the control (Table 1). In presence of $12 \%$ (v/v) OMW the growth of $C$. vulgaris and $M$. braunii was neglectable. A. obliquus did neither grow in $6 \%$ nor in $12 \%$ (v/v) OMW.

A comparison of the growth under dark and light conditions reveals, that the cultivation under dark condition in presence of glucose has a major advantage. This is not only due to the darkening effect of the OMW and therefore decreased photosynthetic activity in cultures grown under 

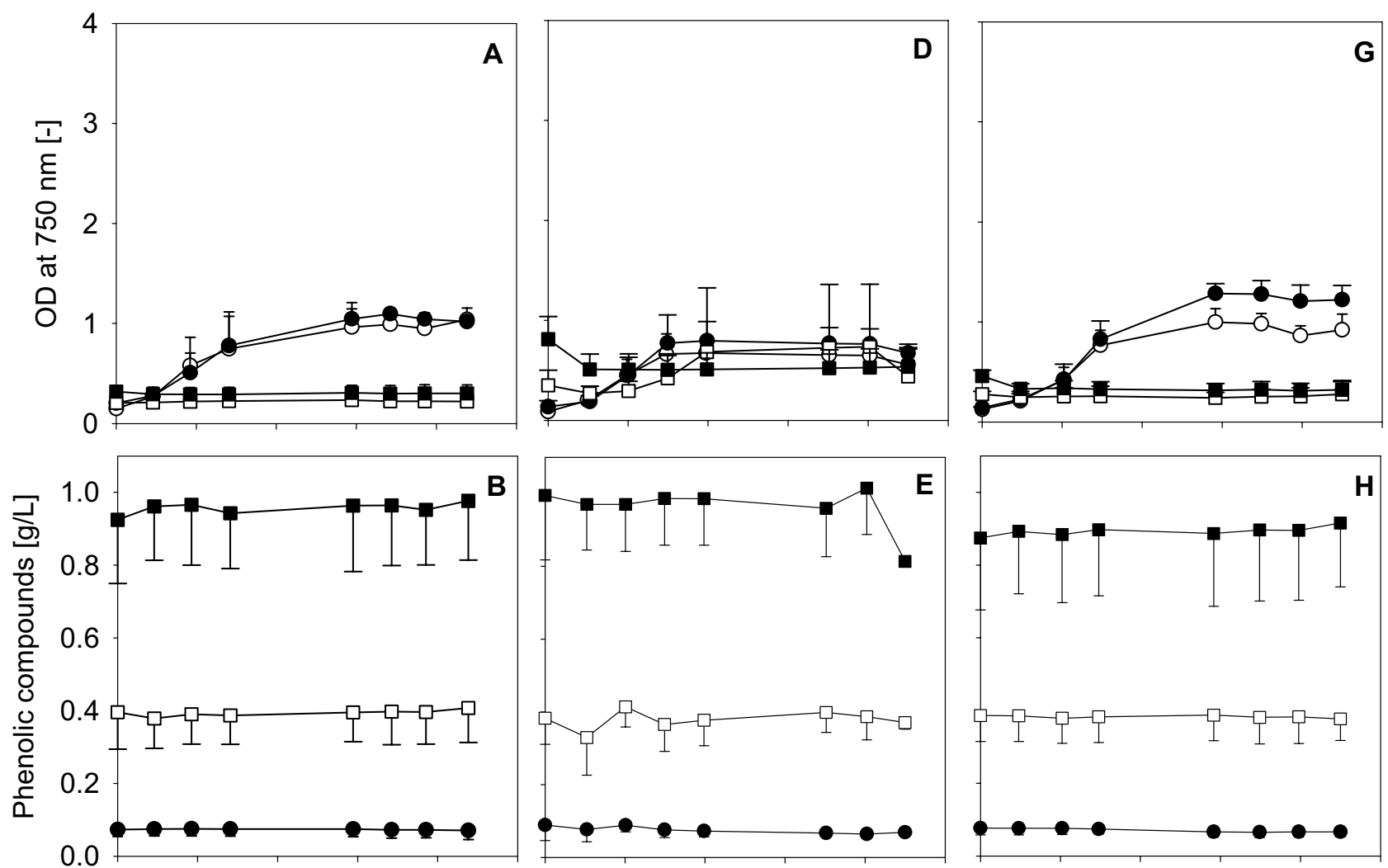

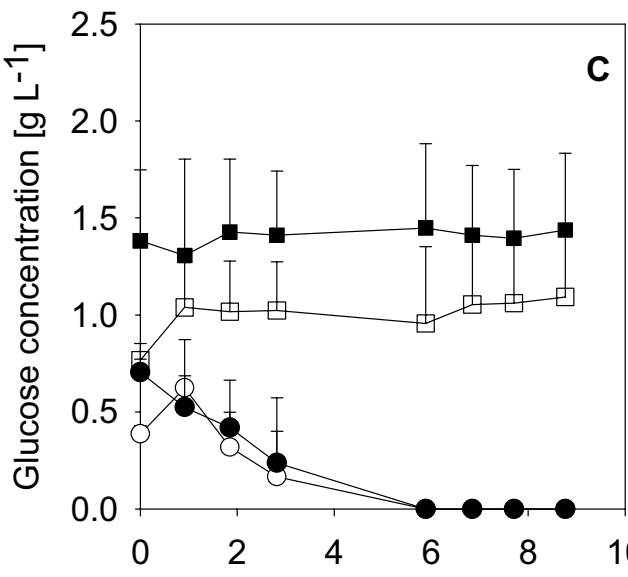

Cultivation time $[\mathrm{d}]$

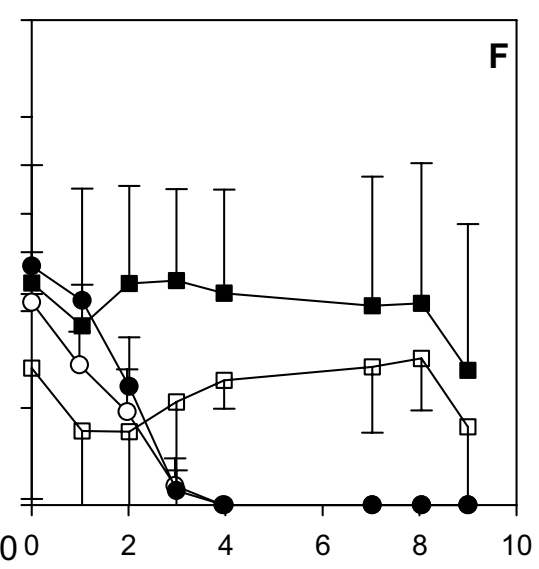

Cultivation time [d]

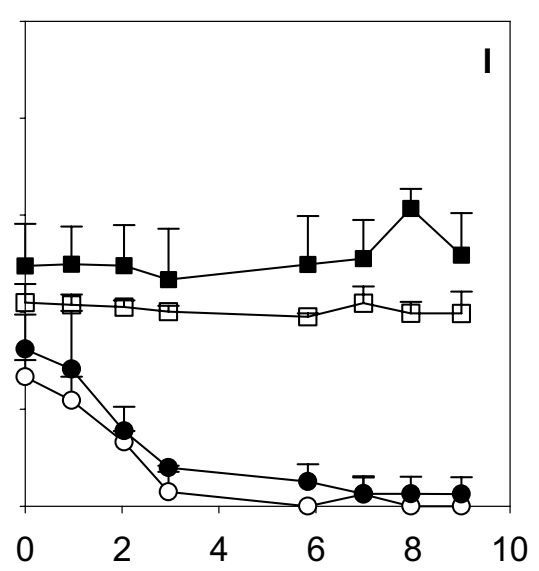

Cultivation time [d]
Fig. 1 Change in optical density (OD), phenolic compounds and glucose concentrations in cultivations under dark conditions for $C$. vulgaris (A, B and $\mathbf{C}), M$. braunii $(\mathbf{D}, \mathbf{E}$ and $\mathbf{F})$ and $A$. obliquus $(\mathbf{G}, \mathbf{H}$

light, but also due to the use of glucose as additional carbon and energy source.

\section{Statistical Analysis of Growth}

Cultivations of all algae carried out under dark conditions did reveal a replicability in control medium and $1 \%(\mathrm{v} / \mathrm{v})$ OMW (p-value >0.05). However, in presence of $6 \%(\mathrm{v} / \mathrm{v})$ and $12 \%(\mathrm{v} / \mathrm{v})$ growth did show statistically significant and I), respectively, carried out in control medium (AF6, open circle), $1 \%(\mathrm{v} / \mathrm{v}$, closed circle), $6 \%$ (v/v, open square) and $12 \%$ OMW (v/v, closed square)

differences among replicates ( $\mathrm{p}$-value $<0.05$ ) due to apparently different effects of OMW on growth.

Cultivation of algae carried out under light conditions did reveal statistically significant differences among replicates irrespective if control medium or 1,6 or $12 \%(\mathrm{v} / \mathrm{v})$ OMW was used. The differences are not explainable by an effect of OMW on growth alone, but due to the generally 

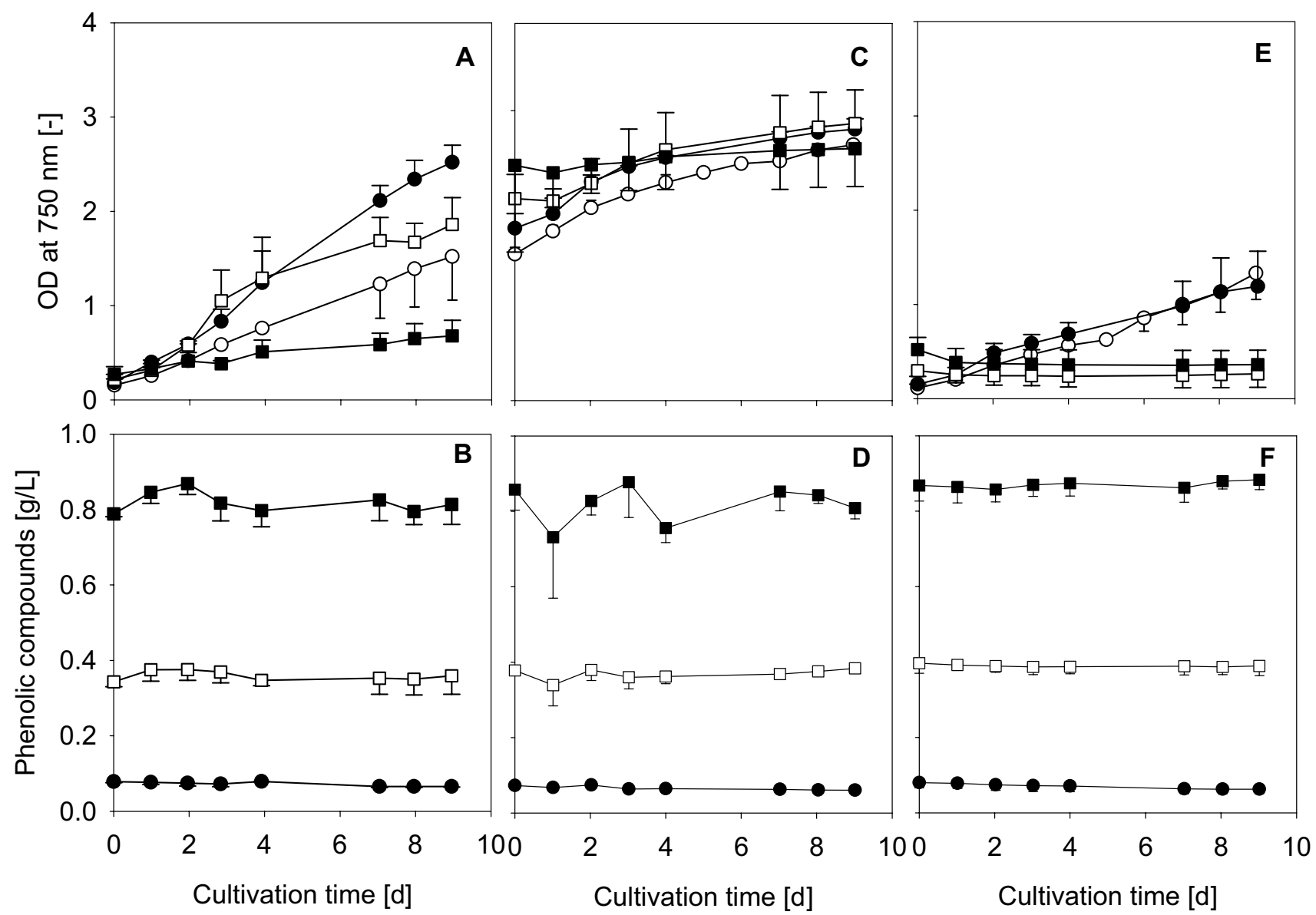

Fig. 2 Change in optical density (OD) and phenolic compounds concentration in cultivations under light conditions for $C$. vulgaris (A and $\mathbf{B})$, M. braunii $(\mathbf{C}$ and $\mathbf{D})$ and A. obliquus $(\mathbf{E}$ and $\mathbf{F})$, respectively,

carried out in control medium (AF6, open circle), $1 \%$ (v/v, closed circle), $6 \%(\mathrm{v} / \mathrm{v}$, open square) and $12 \%$ OMW (v/v, closed square)
Table 1 Summarized results of growth rates $(\mu, 1 / d)$ and percentage of removal of phenolic compounds including standard deviation for all cultivations carried out in control medium, $1 \%(\mathrm{v} / \mathrm{v}), 6 \%$ $(\mathrm{v} / \mathrm{v})$ and $12 \%(\mathrm{v} / \mathrm{v})$ OMW under dark or light condition (n.r.: no or $<5 \%$ removal, n.d.: no determination of growth)

\begin{tabular}{|c|c|c|c|c|c|c|}
\hline Condition & Microalga & & Control & $1 \%(\mathrm{v} / \mathrm{v})$ & $6 \%(\mathrm{v} / \mathrm{v})$ & $12 \%(\mathrm{v} / \mathrm{v})$ \\
\hline \multirow[t]{6}{*}{ Dark } & \multirow[t]{2}{*}{ C. vulgaris } & $\mu$ & $0.54 \pm 0.14$ & $0.54 \pm 0.20$ & n.d & n.d \\
\hline & & Removal & - & $7.0 \pm 7.6^{*}$ & n.r & n.r \\
\hline & \multirow[t]{2}{*}{ A. obliquus } & $\mu$ & $0.65 \pm 0.02$ & $0.65 \pm 0.02$ & n.d & n.d \\
\hline & & Removal & - & $12.8 \pm 2.3^{*}$ & n.r & n.r \\
\hline & \multirow[t]{2}{*}{ M. braunii } & $\mu$ & $0.71 \pm 0.10$ & $0.69 \pm 0.11$ & $0.23 \pm 0.27$ & n.d \\
\hline & & Removal & - & $20.0 \pm 23.5^{*}$ & n.r & n.r \\
\hline \multirow[t]{6}{*}{ Light } & \multirow[t]{2}{*}{ C. vulgaris } & $\mu$ & $0.43 \pm 0.06$ & $0.35 \pm 0.13$ & $0.58 \pm 0.32$ & $0.08 \pm 0.03$ \\
\hline & & Removal & - & $12.3 \pm 6.9^{*}$ & n.r & n.r \\
\hline & \multirow[t]{2}{*}{ A. obliquus } & $\mu$ & $0.40 \pm 0.06$ & $0.41 \pm 0.13$ & n.d & n.d \\
\hline & & Removal & - & $21.1 \pm 10.6^{*}$ & n.r & n.r \\
\hline & \multirow[t]{2}{*}{ M. braunii } & $\mu$ & $0.29 \pm 0.07$ & $0.38 \pm 0.15$ & $0.30 \pm 0.24$ & $0.08 \pm 0.15$ \\
\hline & & Removal & - & $16.7 \pm 2.5^{*}$ & n.r & n.r \\
\hline
\end{tabular}

*The correlation coefficient of linear regression was at least 0.5 reduced growth rates obtained under light conditions compared to dark cultivation (Table 1), and thus the ability of the three strains to grow under light using the experimental settings. 


\section{Removal of Phenolic Compounds and Glucose Consumption}

\section{Cultivation Under Dark Conditions}

The highest removal rate of phenolic compounds was achieved with $M$. braunii with a value of $20 \%$ from the cultures with $1 \%(\mathrm{v} / \mathrm{v})$ OMW (Table 1). C. vulgaris was only able to reduce the phenolic compound load by $7 \%$, whereas A. obliquus removed over $12 \%$ with stable removal rates over three cultivations. Although M. braunii could grow at a slow rate on $6 \%$ OMW, it was not capable of removing phenolic compounds (Table 1). However, an exception was achieved once, where $10 \%$ of phenolic compounds were removed within 9 days (not shown), which is comparable with $\mathrm{Di}$ Caprio et al.'s study from 2015 [48]. Pinto et al. also showed in 2003 that Ankistrodesmus braunii could remove 6-11\% of phenolic compounds in the dark and under light when cultivated with untreated, diluted OMW (resulting start concentration of $0.15 \mathrm{~g} / \mathrm{L}$ phenolic compounds), which is lower compared to our study (20\% removal in the dark with $0.1 \mathrm{~g} / \mathrm{L}$ phenolic compounds), but still comparable [33]. With a Scenedesmus species Di Caprio et al. could show around $50 \%$ removal of phenolic compounds under dark conditions with glucose addition, whereas our cultivations showed only $12 \%$ removal with A. obliquus. However, it has to be noted, that they used a OMW resin extract with $0.1 \mathrm{~g} / \mathrm{L}$ total phenolics, which corresponds with our 1\% OMW cultures, but still depicts a pre-treatment of the OMW [43].

All strains cultivated under dark conditions in control medium and in $1 \%(\mathrm{v} / \mathrm{v}) \mathrm{OMW}$ consumed the added glucose within 3-4 days (Fig. 1 C, F and I), which is also visible in the growth curves (Fig. $1 \mathrm{~A}, \mathrm{D}, \mathrm{G}$ ), where the exponential phase ends and the stationary phase begins. After the consumption of glucose, the microalgae removed the phenolic compounds from the medium. This leads to the statement, that the carbon sources are consumed in a diauxic process. This contradicts to the findings of Di Caprio et al. from 2018, where glucose was not only consumed after 1.5 days, but also the phenolic compounds removal started right from the beginning of cultivation. This however, could be due to the fact, that they used a pre-treated OMW resin extract [43]. As the concentrations of phenolic compounds, which can be removed, are low, no second growth phase is visible in the growth curve in our study. Contrarily, algae cultivated in $6 \%$ and $12 \%(\mathrm{v} / \mathrm{v})$ OMW did neither grow nor remove phenolic compounds.

\section{Cultivation Under Light Conditions}

The cultivations under light conditions showed higher percentages of removal of phenolic compounds compared to dark cultivation. C. vulgaris, A. obliquus and $M$. braunii could remove around $12 \%, 21 \%$ and $17 \%$, respectively, after 9-10 days in cultures with $1 \%(\mathrm{v} / \mathrm{v})$ OMW. No alga could reduce phenolic compounds in $6 \%(\mathrm{v} / \mathrm{v})$ OMW (mean values $<5 \%$, Table 1 ). The phenolic compound removal under light is in accordance to Klekner et al., where Chlorella sp. was cultivated with phenol and completely removed the pollutant within 5 days, whereas the cultivation in the dark showed no removal [49]. It must be noted that the latter cultivation was done without an additional carbon source, which leads to the assumption that the alga was not capable of utilizing phenol as carbon source. Another study by Tikoo et al. on the other hand showed mineralization of pentachlorophenol under light $\left({ }^{14} \mathrm{C}\right.$ labeling $)$ and stated that light is clearly required for $\mathrm{CO}_{2}$ evolution [50]. Pinto et al. cultivated A. braunii in 2003 with OMW ( $0.15 \mathrm{~g} / \mathrm{L}$ phenolic compounds) in the dark (see previous chapter) and also under light and showed slightly lower removal percentages, which were, however, still comparable to the ones in the dark $(6-11 \%)$ [33]. This is in accordance with our findings for $M$. braunii, where the cultivation in the dark $(0.1 \mathrm{~g} / \mathrm{L}$ phenolic compounds) and under light resulted in comparable removal of the phenolic compounds (20 and 17\%, respectively). A Scenedesmus sp. was cultivated with $9 \%$ untreated OMW (0.44 g/L phenolic compounds) by Di Caprio et al. in 2015, where a removal of phenolic compounds of up to $22 \%$ was achieved [48]. This value lies in the same range as our findings with $A$. obliquus cultivated with $1 \%$ OMW $(0.1 \mathrm{~g} / \mathrm{L}$ phenolic compounds).

Continuous illumination may have a positive effect on the viability of microalgae as certain biochemical processes may be activated. Studies by Ishijima et al. showed an elevation of free $\mathrm{Mg}^{2+}$ concentration in spinach under light [51]. As this metal ion is an essential cofactor for over 300 enzymes, among others adenosintriphosphatase, the increase leads to a higher activity of those enzymes [52,53]. According to Hug enzyme activation by light may be by direct mechanisms like the absorption of photons or by indirect mechanisms such as the enhancement of protein synthesis, which activate other processes [54]. Therefore, it is possible that light allows algae cells not only to compensate acidity and toxicity caused by the OMW, but also to utilize phenolic compounds better. However, this needs to be further investigated. The positive effect also subsides with higher amounts of added OMW, as this leads to darkening of the culture, thus inhibiting light permeation to the cells.

Comparing the cultivations under light and dark conditions it is visible, that the one under light benefits to the removal of phenolic compounds. Not only are the achieved percentages of removal higher than under dark conditions, but they were also more stable between the triplicates. Although Markou et al. stated that higher growth rates result in higher removal rates, this was not shown here [55]. The 
positive effect of light in our study may be due to enhanced metabolic pathways, as mentioned by other studies [56-64].

Direct transformation processes of the phenolic compounds like $\mathrm{OH}$-bond rupture or photoionization are assumed to be neglectable as they need rather high energy irradiation (wavelengths in UV range $[65,66]$ ), which were not present in this study, as lamps with a light spectrum from 400 to $720 \mathrm{~nm}$ were used. However, indirect mechanisms like transformation by reactive oxygen species (ROS), such as hydroxyl radicals or photosensitizers, such as nitrite and nitrate, could still be possible, as the provided energy by photons with longer wavelengths are sufficient for their creation in aqueous solutions $[67,68]$.

Generally, irrespective the cultivation conditions and algae used, the found degradation of phenolic compounds in presence of $1 \%(\mathrm{v} / \mathrm{v})$ could be described using a linear regression and all approaches revealed a correlation coefficient $\left(\mathrm{R}^{2}\right)$ of at least 0.5 .

\section{Chances and Challenges of a Microalgae-Based Olive Mill Wastewater Valorization}

OMW is not only rich in phenolic compounds, but also in nitrogen and phosphorous compounds. Particularly the presence of nitrogen and phosphorous makes it a promising nutrient source for the cultivation of microalgae. Furthermore, OMW possesses a resource for water which needs to be managed properly in areas with water scarcity, such as the Mediterranean area. Olive oil production requires enormous amounts of water from agricultural to final product level and a recirculation is needed to proceed with it in the future. A recirculation, however, is challenged by the high concentration of phenolic compounds. This study has shown that microalgae can, to a certain extent, remove phenolic compounds in OMW. However, a dilution of OMW to $6 \%$ $(\mathrm{v} / \mathrm{v})$ of its initial concentration seems necessary to avoid an inhibition by toxic phenolic compounds. A treatment of OMW by microalgae under light conditions alone is challenged by the dark color and a supply of an easily metabolizable carbon source is recommended to foster the growth of microalgae in combination with illumination.

Even though a complete removal of phenolic compounds was not achieved, this study introduced an approach to significantly reduce the concentration of phenolic compounds in prediluted OMW. The chance of a microalgae-based OMW valorization strategy lies in the water-saving aspect. The concentration of phenolic compounds can thereby further be reduced by combining the cultivation of microalgae with other processes, such as the cultivation of $R$. glutinis. The target of further activities should be to decrease the concentration of phenolic compounds to a level which allows the recirculation of OMW in olive oil production.

\section{Conclusions}

Microalgae represent promising candidates for the utilization of waste streams, such as olive mill wastewater (OMW). They are not only capable of removing elevated concentrations of nitrogen and phosphorous compounds and lowering $\mathrm{BOD}_{5}$ and $\mathrm{COD}$ levels, but they may also be applied to reduce toxic pollutants such as phenolic compounds. In the present study it could be shown that the cultivation under light and dark conditions has significant advantages and disadvantages on the growth of microalgae in OMW as well as their capability to remove phenolic compounds from the supernatant. Growth was favoured under dark conditions with glucose addition $(\mu=0.54-0.691 / \mathrm{d})$, while removal of phenolic compounds was favoured under light conditions (12.3-21.1\%). It could also be shown that $M$. braunii is the most promising candidate for novel OMW valorization strategies among the chosen algae in this study, as this strain shows highest removal of $20.0 \%$ and $16.7 \%$ of phenolic compounds under dark and light conditions, respectively.

Acknowledgements The authors acknowledge the financial support from the ERA-Net Cofound Action - under H2020 - and the German Federal Ministry of Education and Research for carrying out the research project "Era CoBioTech 1: Biovalorization of olive mill wastewater (OMW) to microbial lipids and other products via Rhodotorula glutinis fermentation (Rhodolive, 031B0607A)".

Author Contributions Writing - original draft, visualization, writing review and editing; investigation and methodology: AVL; methodology, writing-review and editing, supervision, resources, review and editing: DP.

Funding Open Access funding enabled and organized by Projekt DEAL. This study was funded by the ERA-Net Cofound Action - under H2020 - and the German Federal Ministry of Education and Research for carrying out the research project "Era CoBioTech 1: Biovalorization of olive mill wastewater (OMW) to microbial lipids and other products via Rhodotorula glutinis fermentation (Rhodolive, 031B0607A)".

Data Availability Data can be obtained from the corresponding author.

Code Availability Not applicable.

\section{Declarations}

Conflict of interest The authors declare no conflict of interest or competing interest.

Ethical Approval Not applicable.

Consent to Participate Not applicable. 
Consent for Publication The authors agree on a publication in Waste and Biomass Valorization.

Open Access This article is licensed under a Creative Commons Attribution 4.0 International License, which permits use, sharing, adaptation, distribution and reproduction in any medium or format, as long as you give appropriate credit to the original author(s) and the source, provide a link to the Creative Commons licence, and indicate if changes were made. The images or other third party material in this article are included in the article's Creative Commons licence, unless indicated otherwise in a credit line to the material. If material is not included in the article's Creative Commons licence and your intended use is not permitted by statutory regulation or exceeds the permitted use, you will need to obtain permission directly from the copyright holder. To view a copy of this licence, visit http://creativecommons.org/licenses/by/4.0/.

\section{References}

1. Al-Malah, K., Azzam, M.O., Abu-Lail, N.I.: Olive mills effluent (OMW) wastewater post-treatment using activated clay. Sep. Purif. Technol. 20, 225-234 (2000)

2. Jandera, P.: Methods for the HPLC analysis of phenolic compounds and flavonoids in beer. Beer Health Dis. Prev. (2009). https://doi.org/10.1016/B978-0-12-373891-2.00098-5

3. Sierra, J., Marti, E., Montserrat, G., Cruanas, R., Garau, M.A.: Characterisation and evolution of a soil affected by olive oil mill wastewater disposal. Sci. Total Environ. 279, 207-214 (2001)

4. Cuellar-Bermudez, S.P., et al.: Nutrients utilization and contaminants removal. A review of two approaches of algae and cyanobacteria in wastewater. Algal Res. 24, 438-449 (2017)

5. Doula, M.K., et al.: Olive Mill Waste: Recent Advances for the Sustainable Development of Olive oil Industry, pp. 29-56. Elsevier, Amsterdam (2017)

6. Paraskeva, P., Diamadopoulos, E.: Technologies for olive mill wastewater (OMW) treatment: a review. J. Chem. Technol. Biotechnol. 81(9), 1475-1485 (2006)

7. Allouche, N., Fki, I.: Toward a high yield recovery of antioxidants and purified hydroxytyrosol from olive mill wastewaters. J. Agric. Food Chem. 52, 267-273 (2004)

8. Lopez-Miranda, J., et al.: Olive oil and health: summary of the II international conference on olive oil and health consensus report, Jaen and Cordoba (Spain) 2008. Nutr. Metab. Cardiovasc. Dis. 20(4), 284-294 (2010)

9. Visioli, F., Poli, A.: Antioxidant and other biological activities of phenols from olives and olive oil. Med. Res. Rev. 22(1), 65-75 (2002)

10. Garcia-Gonzalez, D.L., Aparicio, R.: Research in olive oil: challenges for the near future. J. Agric. Food Chem. 58(24), 1256912577 (2010)

11. Kavvadias, V., Doula, M., Theocharopoulos, S.: Long-term effects on soil of the disposal of olive mill waste waters (OMW). Environ. Forensics 15(1), 37-51 (2014)

12. Paredes, M.J., Monteoliva-Sanchez, M.: Effects of waste waters from olive oil extraction plants on the bacterial population of soil. Chemosphere 15(5), 659-664 (1986)

13. Di Caprio, F., Altimari, P., Pagnanelli, F.: Integrated microalgae biomass production and olive mill wastewater biodegradation: optimization of the wastewater supply strategy. Chem. Eng. J. 349, 539-546 (2018)

14. Obied, H.K., Allen, M.S.: Bioactivity and analysis of biophenols recovered from olive mill waste. J. Agric. Food Chem. 53, 823837 (2005)
15. Bisignano, G., Tomaino, A.: On the in-vitro antimicrobial activity of oleuropein and hydroxytyrosol. J. Pharm. Pharmacol. 51, 971-974 (1999)

16. Capasso, R., Evidente, A., Schivo, L., Orru, G., Marciallis, M.A., Cristinzio, G.: Antibacterial polyphenols from olive oil mill waste waters. J. Appl. Bacteriol. 79, 393-398 (1995)

17. Fiorentino, A., Gentili, A., Isidori, M., Monaco, P., Nardell, A., Parrlea, A., Temussi, F.: Envirionmental effects caused by olive mill wastewaters: Toxicity comparison of low-molecular-weight phenol components. J. Agric. Food Chem. 51, 1005-1009 (2003)

18. Mekki, A., Dhouib, A., Feki, F., Sayadi, S.: Assessment of toxicity of the untreated and treated olive mill wastewaters and soil irrigated by using microbiotests. Ecotoxicol. Environ. Saf. 69(3), 488-495 (2008)

19. Barbera, A.C., et al.: Effects of spreading olive mill wastewater on soil properties and crops, a review. Agric. Water Manag. 119, 43-53 (2013)

20. Chartzoulakis, K., et al.: Application of olive mill wastewater to a Cretan olive orchard: effects on soil properties, plant performance and the environment. Agric. Ecosyst. Environ. 138(3-4), 293-298 (2010)

21. Moraetis, D., et al.: Olive mill wastewater irrigation of maize: impacts on soil and groundwater. Agric. Water Manag. 98(7), 1125-1132 (2011)

22. González, L.E., Canizares, R.O.: Efficiency of ammonia and phosphorus removal from a Colombian agroindustrial wastewater by the microalgae Chlorella vulgaris and Scenedesmus dimorphus. Biosource Technol. 60, 259-262 (1997)

23. Hammouda, O., Gaber, A., Abdel-Raouf, N.: Microalgae and wastewater treatment. Ecotoxicol. Environ. Saf. 31, 205-210 (1995)

24. Hammouda, O., Abdel-Raouf, N., Shaaban, M., Kamal, M.: Treatment of mixed domestic-industrial wastewater using microalgae Chlorella sp. J. Am. Sci. 11(12), 303-315 (2015)

25. Hariskos, I., Posten, C.: Biorefinery of microalgae-opportunities and constraints for different production scenarios. Biotechnol. J. 9(6), 739-752 (2014)

26. Liang, Y., Sarkany, N., Cui, Y.: Biomass and lipid productivities of Chlorella vulgaris under autotrophic, heterotrophic and mixotrophic growth conditions. Biotech. Lett. 31(7), 1043-1049 (2009)

27. Posten, C.: Design principles of photo-bioreactors for cultivation of microalgae. Eng. Life Sci. 9(3), 165-177 (2009)

28. Cerniglia, C.E., Gibson, D.T., Van Baalen, C.: Oxidation of naphthalene by cyanobacteria and microalgae. J. Gen. Microbiol. 116, 495-500 (1980)

29. Papazi, A., Kotzabasis, K.: Bioenergetic strategy of microalgae for the biodegradation of phenolic compounds: exogenously supplied energy and carbon sources adjust the level of biodegradation. J. Biotechnol. 129(4), 706-716 (2007)

30. Papazi, A., Ioannou, A.: Bioenergetic strategy of microalgae for the biodegradation of tyrosol and hydroxytyrosol. Zeitschrift für Naturforschung C 72(5-6), 227-236 (2017)

31. Pinto, G., Pollio, A., Previtera, L., Temussi, F.: Biodegradation of phenols by microalgae. Biotech. Lett. 24(24), 2047-2051 (2002)

32. Di Caprio, F., Altimari, P., Iaquaniello, G., Toro, L., Pagnanelli, F.: T. obliquus mixotrophic cultivation in treated and untreated olive mill wastewater. Chem. Eng. Trans. (2018). https://doi.org/ 10.3303/CET1864105

33. Pinto, G., Pollio, A., Previtera, L., Stanzione, M., Temussi, F.: Removal of low molecular weight phenols from olive oil mill wastewater using microalgae. Biotech. Lett. 25(19), 1657-1659 (2003)

34. Lindner, A.V., Pleissner, D.: Utilization of phenolic compounds by microalgae. Algal Res. 42, 101602 (2019) 
35. Di Caprio, F., Visca, A., Altimari, P., Toro, L.: Two stage process of microalgae cultivation for starch and carotenoid production. Chem. Eng. Trans. 49, 415-420 (2016)

36. El-Sheekh, M.M., Ghareib, M.M., Abou-El-Souod, G.W.: Biodegradation of phenolic and polycyclic aromatic compounds by some algae and cyanobacteria. J. Bioremediat. Biodegrad. 03(01), 1-9 (2012)

37. Lima, S.A.C., Castro, P.M.L., Morais, R.: Biodegradation of p-nitrophenol by microalgae. J. Appl. Phycol. 15, 137-142 (2003)

38. Pulz, O., Gross, W.: Valuable products from biotechnology of microalgae. Appl. Microbiol. Biotechnol. 65(6), 635-648 (2004)

39. Spolaore, P., Joannis-Cassan, C., Duran, E., Isambert, A.: Commercial applications of microalgae. J. Biosci. Bioeng. 101(2), 87-96 (2006)

40. Villasclaras, S.S., Sancho, M.M., Caballero, M.E., Pérez, A.D.: Production of microalgae from olive mill wastewater. Int. Biodeterior \& Biodegrad. 38(3-4), 245-247 (1996)

41. Watanabe, M.M., Kawachi, M.: NIES Collection List of Strains Microalgae and Protozoa, Sixth, p. 159. Microbial Culture Collections, National Institute for Environmental Studies, Tsukuba (2000)

42. Atanassova, M., Georgieva, S., Ivancheva, K.: Total phenolic and total flavonoid contents, antioxidant capacity and biological contaminants in medicinal herbs. J. Univ. Chem. Technol. Metall. 46(1), 81-88 (2011)

43. Di Caprio, F., Scarponi, P., Altimari, P., Iaquaniello, G., Pagnanelli, F.: The influence of phenols extracted from olive mill wastewater on the heterotrophic and mixotrophic growth of Scenedesmus sp. J. Chem. Technol. Biotechnol. 93(12), 36193626 (2018)

44. Kessler, E.: Comparative physiology, biochemistry, and the taxonomy of chlorella (Chlorophyceae). Plant Syst. Evol. 125(3), 129-138 (1976)

45. Kessler, E.: Physiological and biochemical contributions to the taxonomy of the genera Ankistrodesmus and Scenedesmus. Arch. Microbiol. 126(1), 11-14 (1980)

46. Hodaifa, G., Martínez, M.E., Sánchez, S.: Influence of $\mathrm{pH}$ on the culture of Scenedesmus obliquus in olive-mill wastewater. Biotechnol. Bioprocess Eng. 14(6), 854-860 (2010)

47. Della Greca, M., Monaco, P., Pinto, G., Pollio, A., Previtera, L., Temussi, F.: Phytotoxicity of low-molecular-weight phenols from olive mill waste waters. Bull. Environ. Contam. Toxicol. 67(3), 0352-0359 (2001)

48. Di Caprio, F., Altimari, P.: Integrated biomass production and biodegradation of olive mill wastewater by cultivation of Scenedesmus sp. Algal Res. 9, 306-311 (2015)

49. Klekner, V., Kosaric, N.: Degradation of phenols by algae. Environ. Technol. 13(5), 493-501 (1992)

50. Tikoo, V., Scragg, A.H., Shales, S.W.: Degradation of pentachlorophenol by microalgae. J. Chem. Technol. Biotechnol. 68, 425-431 (1997)

51. Ishijima, S., Uchibori, A., Takagi, H., Maki, R., Ohnishi, M.: Light-induced increase in free $\mathrm{Mg} 2+$ concentration in spinach chloroplasts: measurement of free $\mathrm{Mg} 2+$ by using a fluorescent probe and necessity of stromal alkalinization. Arch. Biochem. Biophys. 412(1), 126-132 (2003)

52. Pasternak, K., Kocot, J., Horecka, A.: Biochemistry of magnesium. J. Elementol. 15, 601-616 (2012)

53. Wolf, F.I., Cittadini, A.: Chemistry and biochemistry of magnesium. Mol. Asp. Med. 24, 3-9 (2003)
54. Hug, D.H.: The activation of enzymes with light. In: Smith, Kendric C. (ed.) Photochemical and Photobiological Reviews. Springer, Boston (1978)

55. Markou, G., Chatzipavlidis, I., Georgakakis, D.: Cultivation of Arthrospira (Spirulina) platensis in olive-oil mill wastewater treated with sodium hypochlorite. Biores. Technol. 112, 234-241 (2012)

56. Perez-Garcia, O., Bashan, Y.: Microalgal heterotrophic and mixotrophic culturing for bio-refining: from metabolic routes to techno-economics. Algal Biorefineries (2015). https://doi.org/10. 1007/978-3-319-20200-6_3

57. Chen, F., Zhang, Y., Guo, S.: Growth and phycocyanin formation of Spirulina platensis in photoheterotrophic culture. Biotech. Lett. 18(5), 603-608 (1996)

58. Chojnacka, K., Noworyta, A.: Evaluation of Spirulina sp. growth in photoautotrophic, heterotrophic and mixotrophic cultures. Enzyme and Microb. Technol. 34(5), 461-465 (2004)

59. Li, Y., et al.: Effect of light intensity on algal biomass accumulation and biodiesel production for mixotrophic strains chlorella kessleri and chlorella protothecoide cultivated in highly concentrated municipal wastewater. Biotechnol. Bioeng. 109(9), 2222-2229 (2012)

60. Marquez, F.J., Sasaki, K., Kakizono, T., Nishio, N., Nagai, S.: Growth characteristics of Spirulina platensis in mixotrophic and heterotrophic conditions. J. Ferment. Bioeng. 76(5), 408-410 (1993)

61. Ogawa, T., Aiba, S.: Bioenergetic analysis of mixotrophic growth in Chlorella vulgaris and Scenedesmus acutus. Biotechnol. Bioeng. 23, 1121-1132 (1981)

62. Aparicio, P.J., Quinones, M.A.: Blue light, a positive switch signal for nitrate and nitrite uptake by the green alga Monoraphidium braunii. Plant Physiol. 95, 374-378 (1991)

63. Aparicio, P.J., Witt, F.G., Ramirez, J.M., Quinones, M.A., Balandin, T.: Blue-light-induced $\mathrm{pH}$ changes associated with $\mathrm{NO}_{3}^{-}$, $\mathrm{NO}_{2}{ }^{-}$and $\mathrm{Cl}^{-}$uptake by the green alga Monoraphidium braunii. Plant, Cell Environ. 17, 1323-1330 (1994)

64. Giraldez, N., Aparicio, P.J., Quinones, M.A.: Blue light requirement for $\mathrm{HCO}_{3}{ }^{-}$uptake and its action spectrum in Monoraphidium braunii. Photochem. Photobiol. 68(3), 420-426 (1998)

65. Su, R., Kesavan, L., Jensen, M.M.: Selective photocatalytic oxidation of benzene for the synthesis of phenol using engineered $\mathrm{Au}-\mathrm{Pd}$ alloy nanoparticles supported on titanium dioxide. Chem. Commun. (2014). https://doi.org/10.1039/C4CC04024D

66. Richard, C., Grabner, G.: Mechanism of phototransformation of phenol and derivatives in aqueous solution. In: The Handbook of Environmental Chemistry, pp. 217-239. Springer, Berlin (1999)

67. Calza, P., Vione, D., Novelli, A., Pelizzetti, E., Minero, C.: The role of nitrite and nitrate ions as photosensitizers in the phototransformation of phenolic compounds in seawater. Sci. Total Environ. 439, 67-75 (2012)

68. Grabitz, E., et al.: Abiotic and biotic degradation of five aromatic organosilicon compounds in aqueous media-structure degradability relationships. J. Hazard Mater. 392, 122429 (2020)

Publisher's Note Springer Nature remains neutral with regard to jurisdictional claims in published maps and institutional affiliations. 